\title{
A study on prevalence of reproductive tract infections and health seek- ing behaviour among the women in an urban slum area of Karimnagar
}

\author{
Saleha Afreen ${ }^{1}$, Vidhya Wilson², Surendranath Sai ${ }^{3}$ \\ ${ }^{1}$ Tutor, ESIC Medical College, Hyderabad, 2Professor, Rajiv Gandhi Institute of Medical Sciences, Adilabad, ${ }^{3}$ Professor, Prathima \\ Institute of Medical Sciences, Karimnagar.
}

Address for correspondence: Dr. SalehaAfreen, Tutor, Department of Community Medicine, ESIC Medical College, Sanathnagar, Hyderabad.

Email: salehaafreen.sa@gmail.com

\section{ABSTRACT}

Introduction: Reproductive tract infections (RTIs) are recognized as public health problem and rank second after maternal morbidity and mortality because of loss of healthy life among women of reproductive age. National family Health Survey-4 (2015-2016) has reported that $23.5 \%$ of the women were suffering from reproductive tract infections. RTIs are considered not just a medical problem but also seen as a symptom of wider social pathology in the community.

Objectives: To study the prevalence of reproductive tract infections and its socio-demographic determinants among the women of reproductive age group (15-49 years) in urban slums. To assess the health seeking behavior among the women suffering from reproductive tract infections.

Methodology: A cross-sectional study was conducted among the women of reproductive age group (15-49 yrs) residing in slums of urban field practice area of tertiary care teaching hospital during the period from June 2017 to October 2018. A total of 300 women were selected by simple random sampling technique. A pre designed and pre tested semi-structured questionnaire was used for collecting the data.Thedata was analyzed using SPSS 20.0 Soft ware.

Results and Conclusion: The prevalence of RTIs among the women was $22.3 \%$. Vaginal discharge, 57(85\%) and pain abdomen 39 (58.2\%) were the most common symptoms. The socio demographic factors significantly associated with RTIs were illiteracy and low socio economic status. Women using cloth during menstruation and having dysmenorrhea were found to be associated risk factors for RTIs. Women having $\geq 3$ children, $26(29.2 \%)$ and using IUCD, $16(50 \%)$ as a method of contraception were found to be at risk of RTIs. Health seeking behavior of the women suffering from RTI was found to be poor, $13(19.4 \%)$

Keywords: Reproductive tract infections, prevalence, determinants, health seeking behavior, women, urban slums.

\section{INTRODUCTION}

Reproductive tract infections (RTIs) represent a major public health problem and is more prevalent in developing countries and the consequences of RTIs are potentially devastating. ${ }^{1}$ Reproductive tract infections are the most neglected health problem affecting health and social well-being of women in their productive age. ${ }^{2}$ National family Health Survey-4 (2015-2016) has reported that $23.5 \%$ of women in India have one or more reproductive tract infections. ${ }^{3}$

The social factors such as cultural barriers, poor understanding of symptoms, lack of privacy, lack of a female doctor at the health facility, the cost of treatment, social stigma, and fear of internal check-up lead to delay in seeking treatment. ${ }^{4}$ Despite of availability of health services, majority of the symptomatic women bears silence because of shyness and social stigma and continue to suffer from RTIs especially in rural \& urban slum areas. ${ }^{5}$ Low level of awareness regarding sexual and reproductive health ${ }^{6}$ as well as low female literacy, cultural factors and taboos withhold the women from seeking health care for RTIs. ${ }^{7}$

In view of this the present study was conducted to assess the prevalence of RTIs and health seeking behavior among the women suffering from reproductive tract infections.

\section{OBJECTIVES:}

1) To assess the prevalence of reproductive tract infections among the women of reproductive age group (15-49 years) in urban slums.

2) To determine the socio-demographic factors associated with reproductive tract infections.

3) To assess the health seeking behavior among the women suffering from reproductive tract infections. 


\section{MATERIALS AND METHODS:}

A cross-sectional study was conducted among the women of reproductive age group (15-49 yrs) residing in slums of urban field practice area of a tertiary care teaching institution from June 2017 to October 2018. A list of all the houses in the study area were obtained from the household survey registers maintained at the urban health centre. Out of total 420 houses, 300 houses were selected by simple random sampling technique using random number table. Only one woman of age between 15-49 yrs from each of the selected houses was included in the study. In case if more than one woman was found in the house belonging to the same age group then the women was selected randomly by lottery method. If the selected house was found to be locked or the woman was unavailable due to any reason immediate next house was selected. A predesigned and pretested semi structured proforma was used for data collection. The data was collected by verbal interview technique. A written informed consent was taken before conducting the interview. An institutional ethical

Based on the symptoms stated by women, it was observed that $67(22.3 \%)$ of the women were suffering from RTI (Fig 1 ).

TABLE 1: SYMPTOMS RELATED TO RTIS

\begin{tabular}{|l|l|}
\hline \multicolumn{1}{|c|}{ SYMPTOMS * } & NUMBER (\%) (n =67) \\
\hline Vaginal discharge & $57(85 \%)$ \\
\hline Lower abdominal pain & $39(58.2 \%)$ \\
\hline Itching of genitals & $27(40.2 \%)$ \\
\hline Burning Micturation & $9(13.4 \%)$ \\
\hline Genital ulcer & $4(5.9 \%)$ \\
\hline
\end{tabular}

Most common symptom related to $\mathrm{RTI}$, were vaginal discharge in $57(85 \%)$ of the women, lower abdominal pain in $39(58.2 \%)$ of the women and itching of genitals in $27(40.2 \%)$ of the women(Table 1).Among $67(22.3 \%)$ of the women suffering from RTI, $23(34.3 \%)$ of the women had recurrence of RTI. Out of which $12(52.2 \%)$ of the women took treatment in the past.

\section{TABLE 2: SOCIO DEMOGRAPHIC FACTORS AND RTI}

\begin{tabular}{|c|c|c|c|c|c|c|}
\hline \multirow{2}{*}{ SI.No. } & \multirow{2}{*}{ VARIABLE } & \multicolumn{2}{|c|}{ RTI (n = 300) } & \multirow{2}{*}{ TOTAL } & \multirow{2}{*}{$\chi^{2}$} & \multirow{2}{*}{$P$ - value } \\
\hline & & YES & NO & & & \\
\hline 1 & $\begin{array}{l}\text { AGE GROUP } \\
\text { Less than } 20 \\
21-30 \\
\text { Above } 30\end{array}$ & $\begin{array}{l}10(21.7 \%) \\
30(24.8 \%) \\
27(20.3 \%)\end{array}$ & $\begin{array}{l}36(78.3 \%) \\
91(75.2 \%) \\
106(79.7 \%)\end{array}$ & $\begin{array}{l}46 \\
121 \\
133\end{array}$ & 0.74 & 0.68 \\
\hline 2 & $\begin{array}{l}\text { EDUCATION } \\
\text { Illiterate } \\
\text { Schooling } \\
\text { Intermediate \& above }\end{array}$ & $\begin{array}{l}18(34.6 \%) \\
25(22 \%) \\
24(18 \%)\end{array}$ & $\begin{array}{c}34(65.4 \%) \\
89(78 \%) \\
110(82 \%)\end{array}$ & $\begin{array}{l}52 \\
114 \\
134\end{array}$ & 13.44 & 0.02 \\
\hline 3 & $\begin{array}{l}\text { SOCIO ECONOMIC STATUS } \\
\text { I } \\
\text { II } \\
\text { III } \\
\text { IV } \\
\text { V }\end{array}$ & $\begin{array}{l}7(24.1 \%) \\
6(13.6 \%) \\
13(19.1 \%) \\
23(19.8 \%) \\
18(41.9 \%)\end{array}$ & $\begin{array}{l}22(75.9 \%) \\
38(86.4 \%) \\
55(80.9 \%) \\
93(80.2 \%) \\
25(58.1 \%)\end{array}$ & $\begin{array}{l}29 \\
44 \\
68 \\
116 \\
43\end{array}$ & 12.25 & 0.016 \\
\hline 4 & $\begin{array}{l}\text { MARITAL STATUS } \\
\text { Unmarried } \\
\text { Married }\end{array}$ & $\begin{array}{l}6(12.5 \%) \\
61(24.2 \%)\end{array}$ & $\begin{array}{c}42(87.5 \%) \\
191(75.8 \%)\end{array}$ & $\begin{array}{l}48 \\
252\end{array}$ & 3.18 & 0.037 \\
\hline
\end{tabular}


It was observed that majority of the women suffering with RTI, $30(24.8 \%)$ were in the age group $21-30$ years. $\mathrm{RTI}$ cases were observed to be higher among illiterate women, 18 (34.6\%) compared to those who were educated up to intermediate and above $24(18 \%)(p=0.02)$. Majority of the women 18(41.9\%) who belonged to socio economic class V, were found to be suffering from RTIs as compared to class I and II, 7(24.1\%) and $6(13.6 \%)$ respectively $(p=0.016)$. Most of the married women $61,(24.2 \%)$ were found to be suffering from RTIs as compared to unmarried women, $6(12.5 \%)(p=0.037)$ (Table 2).

\section{Table 3: ASSOCIATION BETWEEN RTIS AND ITS RISK FACTORS}

\begin{tabular}{|c|c|c|c|c|c|c|}
\hline \multirow{2}{*}{ SI.No. } & \multirow{2}{*}{ RISK FACTORS } & \multicolumn{2}{|c|}{ RTI } & \multirow{2}{*}{ TOTAL } & \multirow{2}{*}{$\chi^{2}$} & \multirow{2}{*}{$P$ - value } \\
\hline & & YES & NO & & & \\
\hline 1 & $\begin{array}{l}\text { MENSTRUAL PRACTICE }(\mathbf{n = 3 0 0 )} \\
\text { Sanitary pad } \\
\text { Fresh cloth } \\
\text { Reused cloth }\end{array}$ & $\begin{array}{l}34(17.3 \%) \\
18(35.3 \%) \\
15(28.8 \%)\end{array}$ & $\begin{array}{r}163(82.7 \%) \\
33(64.7 \%) \\
37(71.2 \%)\end{array}$ & $\begin{array}{r}197 \\
51 \\
52\end{array}$ & 9.135 & 0.01 \\
\hline 2 & $\begin{array}{l}\text { DYSMENORRHOEA }(n=300) \\
\text { Present } \\
\text { Absent }\end{array}$ & $\begin{array}{l}28(34.1 \%) \\
39(17.9 \%)\end{array}$ & $\begin{array}{l}54(65.9 \%) \\
179(82.1 \%)\end{array}$ & $\begin{array}{r}82 \\
218\end{array}$ & 9.078 & 0.002 \\
\hline \multirow[t]{4}{*}{3} & $\begin{array}{l}\text { PARITY }(\mathbf{n = 2 5 2 )} \\
\text { Nulliparous } \\
1-2 \text { children } \\
\geq 3 \text { children }\end{array}$ & $\begin{array}{l}5(20.8 \%) \\
30(21.6 \%) \\
26(29.2 \%)\end{array}$ & $\begin{array}{l}19(79.2 \%) \\
109(78.4 \%) \\
63(70.8 \%)\end{array}$ & $\begin{array}{r}24 \\
139 \\
89\end{array}$ & 11.81 & 0.03 \\
\hline & $\begin{array}{l}\text { CONTRACEPTIVE METHODS } \\
\text { (n=252) } \\
\text { Barrier/condom } \\
\text { IUCD } \\
\text { Oral pills/ } \\
\text { Injectable } \\
\text { Tubectomy } \\
\text { None }\end{array}$ & $\begin{array}{l}0(0 \%) \\
16(50 \%) \\
3(37.5 \%) \\
5(15.2 \%) \\
37(20.9 \%)\end{array}$ & $\begin{array}{c}2(100 \%) \\
16(50 \%) \\
5(62.5 \%) \\
28(84.8 \%) \\
140(79.1 \%)\end{array}$ & $\begin{array}{r}2 \\
32 \\
8 \\
\\
33 \\
177\end{array}$ & 15.54 & 0.003 \\
\hline & $\begin{array}{l}\text { ABORTION }(\mathbf{n}=\mathbf{2 5 2}) \\
\text { Yes } \\
\text { No }\end{array}$ & $\begin{array}{r}9(37.5 \%) \\
52(22.8 \%)\end{array}$ & $\begin{array}{r}15(62.5 \%) \\
176(77.2 \%)\end{array}$ & $\begin{array}{r}24 \\
228\end{array}$ & 4.22 & 0.121 \\
\hline & $\begin{array}{l}\text { MTP(n=252) } \\
\text { Yes } \\
\text { No }\end{array}$ & $\begin{array}{r}3(21.4 \%) \\
58(24.4 \%)\end{array}$ & $\begin{array}{l}11(78.6 \%) \\
180(75.6 \%)\end{array}$ & $\begin{array}{r}14 \\
238\end{array}$ & 0.64 & 0.72 \\
\hline & $\begin{array}{l}\text { INFERTILITY ( } \mathbf{n}=\mathbf{2 5 2}) \\
\text { Yes } \\
\text { No }\end{array}$ & $\begin{array}{l}2(22.2 \%) \\
59(24.3 \%)\end{array}$ & $\begin{array}{l}7(77.8 \%) \\
184(75.7 \%)\end{array}$ & $\begin{array}{l}9 \\
243\end{array}$ & 0.02 & 0.88 \\
\hline
\end{tabular}

Majority of the women, $18(35.3 \%)$ who were using fresh cloth and $15(28.8 \%)$ of women who used reused cloth were having RTIs than women who were using sanitary pad, 34(17.3\%) $(p=0.01)$.Out of total 82 women who were suffering from dysmenorrhoea, 28(34.1\%) were having RTIs compared to women not having dysmenorrhoea, 39(17.9\%) $(p=0.002)$. Majority of the women, $26(29.2 \%)$ who were having $=3$ children were found to be suffering from RTIs.A statistically significant difference was observed between parity and RTIs $(p=0.03)$. Half of the women, $16(50 \%)$ who were using IUCD as a method of contraception were having symptoms of RTIs $(p=0.003)$. (Table 3) 
FIG 2: HEALTH SEEKING BEHAVIOUR AMONG THE WOMEN SUFFERING FROM RTI
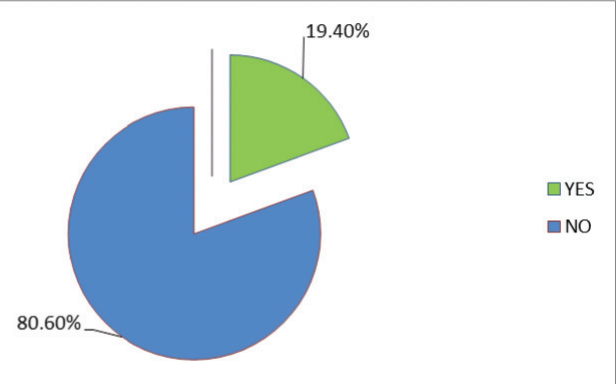

Out of $67(22.3 \%)$ of women suffering from RTI, only $13(19.4 \%)$ took treatment for RTI but majority, 54(80.6\%) did not take treatment for present complaints (Fig 2).

TABLE 4: REASONS FOR NOT SEEKING TREATMENT FOR RTI

\begin{tabular}{|l|c|}
\hline \multicolumn{1}{|c|}{$\begin{array}{c}\text { REASONS FOR NOT TAKING } \\
\text { TREATMENT }\end{array}$} & $\begin{array}{c}\text { NUMBER (\%) } \\
\text { (n=54) }\end{array}$ \\
\hline Did not think it to be serious problem & $25(46.3 \%)$ \\
\hline Felt shy to discuss problem & $12(22.2 \%)$ \\
\hline No time from household work & $17(31.5 \%)$ \\
\hline
\end{tabular}

Out of $54(80.6 \%)$ women who did not seek treatment for RTI, Majority 25(46.3\%) did not consider it to be a serious problem and $17(31.5 \%)$ said they did not have time from house hold work. $12(22.2 \%)$ felt shy to discuss the problem (Table 4).

\section{DISCUSSION}

In the current study, the prevalence of RTIs was found to be $67(22.3 \%)$ which was near to the finding of National family Health Survey-4 (2015-2016), 23.5\%. ${ }^{3}$ In similar studies, the prevalence of RTI was found to be $26.8 \%$ \& $29.15 \% .{ }^{8,2}$ Vaginal discharge was the most commonly observed symptom, $57(85 \%)$ followed by lower abdominal pain $39(58.2 \%)$ and itching of genitals, $27(40.2 \%)$. Similar were the findings reported by Nandan D. et al in their study where commonest symptom of RTIs were vaginal discharge (94\%) followed by lower abdominal pain $(55 \%)^{9}$ Where as in a study by Kanchana B. Gawande et al vaginal discharge was found in $53.9 \%$ of the women. ${ }^{10}$

The prevalence of RTIs was found to be more in the women who were belonging to 21-30 years of age group, $30(24.8 \%)$. Similar were the findings in other studies were the prevalence of RTI was maximum in the age group, 20-30yrs, $(41.8 \%)^{11}$ and in the age group of $26-30$ years, $(33.9 \%) .{ }^{12} \mathrm{RTIs}$ cases were seen to be significantly higher in illiterate women, $18(34.6 \%)$, comparatively less cases were observed among the women who were educated up to intermediate and above, $24(18 \%)(p=0.02)$. A similar study conducted in Andhra Pradesh also observed higher prevalence of RTIs inilliterate women, $(34.1 \%)$ as compared to degree and above group,
(21.4\%). ${ }^{7}$ In a study done in Rajasthan, it was observed that $29.5 \%$ of the women with RTIs were illiterate and $22.8 \%$ of the women were educated up to primary school. ${ }^{13}$ The present study revealed that the prevalence of RTIs decrease with an increase in the level of education. In this study, $18(41.9 \%)$ of the women who were belonging to class $\mathrm{V}$ were found to be suffering from RTIs as compared to class I, 7(24.1\%). Sreelatha C.Y et al and Jyoti Pawanarkar\&Kusum Chopra, in their study reported that women belonging to low income group have high prevalence of RTI, $(52.5 \%)$ \& (36\%) respectively. ${ }^{1,2}$ Most of the married women, $61(24.2 \%)$ were found to be suffering from RTIs compared to $6(12.5 \%)$ of unmarried women $(p=0.037)$. Similar observations were found in other study were $27.9 \%$ of married women had RTIs and only $1 \%$ of unmarried women were found to be having symptoms of RTI $(p<0.0001){ }^{13}$

High prevalence of RTIs was seen in women who used fresh cloth, $18(35.3 \%)$ or reused cloth, $15(28.8 \%)$ than women who used sanitary pad, $34(17.3 \%)$ and the difference was found to be significant $(p=0.01)$. Similar study conducted in Haryanareported high prevalence of RTI, (53.8\%) in women using dirty clothes during menstruation. ${ }^{3}$ The RTIs symptoms were more among women who had dysmenorrhoea, 28 (34.1\%) than women who were not having dysmennorrhoea, 39(17.9\%) $(p=0.002)$. A study done in Chennai revealed that RTI symptoms were 4.2 times more common in women who had dysmenorrhoea $(P=0.001){ }^{4}$

RTIs was present in $26(29.2 \%)$ of the women who were having $=3$ children as compared to women having $1-2$ children, 30(21.6\%) and nulliparous women, $5(20.8 \%)(p=$ $0.03)$. Similar results were found in other study were the prevalence of RTIs was found to be more in the women who had 1-2 children (54.1\%) as compared with women who had no children, $(22.5 \%)(p=0.04) .{ }^{1}$ About $16(50 \%)$ of the women who were using IUCD as a method of contraception were having RTIs as compared to the women who were using other contraceptive method. Higher prevalence of RTI was also observed among the women using IUCD in the studies conducted in Rajasthan and Haryana $37.6 \%$ \& 38.8\% respectively. ${ }^{13}$

It was observed that, 9(37.5\%) of women who were having history of abortion were suffering from RTIs. In a study done by Dr. Anitha et al it was observed that $24(53.3 \%)$ of the women who had history of one or more abortion were suffering from RTIs. ${ }^{14}$

The present study observed that, $3(21.4 \%)$ of the women who had undergone MTP were having symptoms of RTIs. In a study by GayatriS. Desai and R.M Patel RTI symptoms were seen in $1.6 \%$ of the women who had undergone MTP. ${ }^{15} \mathrm{Among}$ the women who were suffering from infertility, $2(22.2 \%)$ of the women had RTIs. In a study conducted in New Delhi, 58 (29\%) of the infertile women were symptomatic for RTI. $^{2}$ 
The present study shows that among 67(22.3\%) of the women suffering from RTI, only $13(19.4 \%)$ took treatment for RTI. In a similar study, comparatively more number of women sought treatment for RTI symptoms, $46.2 \% .{ }^{14}$

In this study it was observed that out of $54(80.6 \%)$ women who did not seek treatment for RTI, 25(46.3\%) of the women did not consider it to be a serious problem, $17(31.5 \%)$ said they did not have time from household work and $12(22.2 \%)$ felt shy to discuss the problem. In a study conducted in Bangalore the reasons stated for not seeking treatment for RTI were $57.3 \%$ of the women said these symptoms were common and normal for women, other reasons were feeling shy to discuss the problem and too busy in routine work or lack of time. ${ }^{2}$

\section{CONCLUSIONS:}

The prevalence of RTIs among the women was $22.3 \%$. The socio demographic factors significantly associated with RTIs were illiteracy and low socio economic status. High prevalence of RTIs was seen in women who used fresh cloth and reused cloth as compared to the women who were using sanitary pad. The prevalence of RTIs was found to be more in the women who were using IUCD, 16(50\%) as a method of contraception. Very few women, $13(19.4 \%)$ sought treatment for RTIs and none of the partner was found to be simultaneously treated for RTIs.

\section{ACKNOWLEDGEMENT:}

We are grateful to the Department of Community Medicine, Prathima Institute of Medical Sciences, Karimnagar for their kind support in conducting the study.

\section{REFERENCES}

1. Rathod DS, Shelke AD, Naik DB, Kesari PM. Prevalence of reproductive tract infections and sexually transmitted infections among married women in the reproductive age group in urban slum of Bidar, Karnataka. 2017;4(11):4182-5.

2. Ratnaprabha GK, SulekhaThimmaiah, Avita Rose Johnson NR. Prevalence and awareness of reproductive tract infections among women in select underprivileged areas of Bangalore city. 2015;4(12):1691-6.

3. RakhiDandona AP and LD. A review of national health surveys in India. 2016;(February):286-96.

4. Jaya Chaturvedi. Screening of Married Women in the Reproductive Age Group for Reproductive Tract Infections in a Village of Garhwal. South East Asian Stud Man. 2000;134-8.

5. Mamta N kaur. Reproductive Tract Infections?: Prevalence and Health Seeking Behaviour among Women of Reproductive Age Group. 2014;3(4):138-42.

6. Mani G, Annadurai K, Danasekaran R. Tamil Nadu-A
Community Based Study [Internet]. Vol. 12, Online J Health Allied Scs. 2013 [cited 2018 Nov 10]. Available from: https://www.ojhas.org/issue47/2013-3-3.pdf

7. B.Sri Devi and N. Swarnalatha.Prevalence of RTI/STI among reproductive age women (15-49 YEARS) in urban slums of Tirupati Town, Andhra Pradesh. Heal PopulPerspect Issues. 2007;30(1):56-70.

8. Shailendra K.B. Hegde1, Twinkle Agrawal2, Naveen Ramesh2, Medha Sugara2, Preethi M Joseph2, Shipthi Singh2 ST. Reproductive tract infections among women in a peri-urban under privileged area in Bangalore, India: Knowledge, prevalence, and treatment seeking behavior. Ann Trop Med Public Heal. 2013;6(2):215-20.

9. Roy S ND. Development towards achieving health/ reproductive health for all and millennium development goals: A critical appraisal for strengthening action programmes (Part-II). Heal PopulPerspect Issues. 2007;30(3):150-76.

10. Gawande KB, Srivastava AS, Kumar P. Reproductive tract infection and health seeking behaviour?: a cross sectional community based study. 2018;5(4):1524-8.

11. Sreelatha CY, Sumana M, Sundar M, Sreeranga A, Pavithra P. Prevalence of symptoms of reproductive tract infections among married reproductive age group women in selected rural areas of Hassan, Karnataka, India. 2017;4(1):206-10.

12. Pawanarkar J, Chopra K. prevalence of lower reproductive tract infection in infertile women[Internet]. Vol. 27, Health and Population-Perspectives and Issues. 2004 [cited 2018 Nov 4]. Available from: http://medind.nic.in/hab/t04/i2/ habt04i2p67.pdf

13. Rathore, Monica, S S swami B. G. community based study of self reported morbidity of reproductive tract infection Among the women of reproductive age in rural area of rajasthan. Indian J community Med. 2003;xxviii(3).

14. Anitha S, Dharmaraj D, Duttagupta KK, Abhinaya B, Amrithalekha AK, Arvind N, et al. Reproductive Tract Infections among Women of Reproductive Age Group ( 15-49 Years ) - A Chennai Based Study. 2016;15(4):74-8.

15. Desai GS, Patel RM. Incidence of reproductive tract infections and sexually transmitted diseases in India: levels and differentials. J FamWelf [Internet]. 2011;57(2):48-5. Available from: http://medind.nic.in/jah/t11/i2/ jaht11i2p48.pdf

How to cite this article : Saleha Afreen, Vidhya Wilson, Surendranath Sai. A study on prevalence of reproductive tract infections and health seeking behaviour among the women in an urban slum area of Karimnagar. Perspectives in Medical Research. 2020; 8(1):29-33

Sources of Support: Nil,Conflict of interest:None declared. 